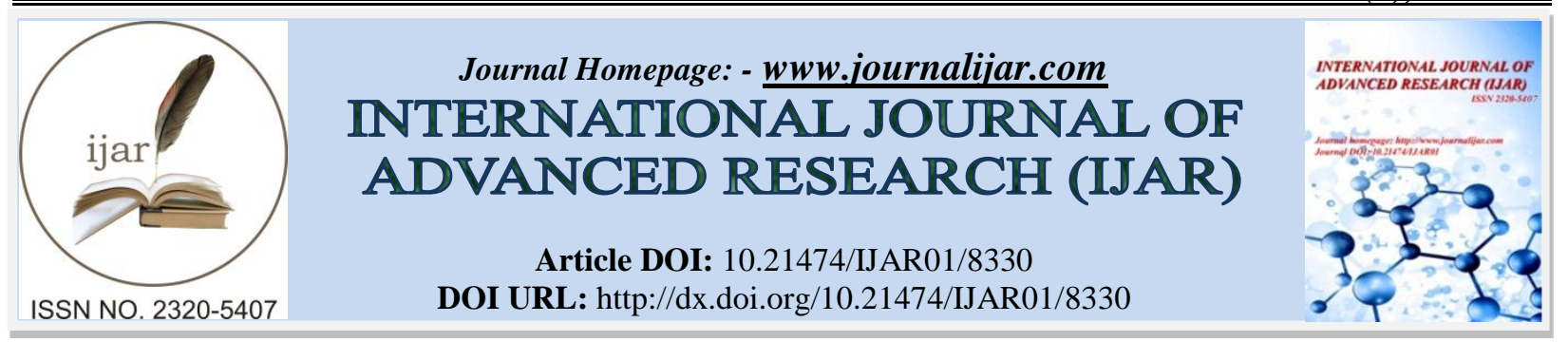

RESEARCH ARTICLE

\title{
ANALYSIS OF LEVELS OF ACRYLAMIDE IN (SOLANUM TUBEROSUM) POTATO CHIPS AND CRISPS.
}

\author{
Nyabaro Obed Mainya ${ }^{1}$, Lusweti Kituyi ${ }^{2}$ And Tabitha Wanjau ${ }^{1}$. \\ 1. Department of Chemistry, Kisii University, Kisii-Kenya. \\ 2. Department of Chemistry, University of Eldoret, Eldoret-Kenya. \\ 3. Department of Health sciences, Kisii University, Kisii, Kenya.
}

\section{Manuscript Info}

Manuscript History

Received: 08 November 2018

Final Accepted: 10 December 2018

Published: January 2019

Key words:-

Toxicology, Acrylamide, Carcinogen, Neurotoxicant, chromatography.

\begin{abstract}
In the recent past scientists in Britain, Sweden and South Africa have discovered that the process of cooking starchy foods under high temperatures produces acrylamide in those foods. The discovery of acrylamide in some cooked starchy foods in 2002 prompted concerns about the carcinogenicity of those foods. Following this discovery in April 2002 on the presence of acrylamide majorly in carbohydrate rich foods, intensive investigations have been undertaken, involving the analysis, occurrence, chemistry, toxicology and potential health risk of this contaminant in the human diet. Acrylamide has been classified as a Group 2A carcinogen and thus remains a suspected human carcinogen and a neurotoxicant that calls for a concerted effort to minimize its presence in all human diets. Fried products including Potato fries and crisps have been reported to contain high levels of acrylamide, a potential carcinogenic substance of great concern not only to consumers. The study aimed at establishing the levels of acrylamide in Potato fries and crisps sold in the Kenyan market. Samples were analytically prepared before analysis before run in the instrument to determine the moisture content, acrylamide presence, its concentration and colour according to food and drugs administration (FDA) method of analysis using a high Perfomance liquid chromatography and thus raise awareness of its harmfulness to the consumers.
\end{abstract}

Copy Right, IJAR, 2018,. All rights reserved.

\section{Introduction:-}

Starchy foods are harmful to the human health; in the recent past scientists in Britain have discovered that the process of cooking starchy foods under high temperatures produces acrylamide in those foods [22]. The discovery of acrylamide in some cooked starchy foods in 2002 prompted concerns about the carcinogenicity of those foods [43]. Cooking starchy foods such as chips, Potato fries, and bread at high temperatures $\left(120^{\circ} \mathrm{C}\right)$ leads to the production of acrylamide in the heating process. Following the discovery of the presence of acrylamide majorly in carbohydrate rich foods, intensive investigations have been undertaken, involving the analysis, occurrence, chemistry, toxicology and potential health risk of this contaminant in the human diet [36].

Corresponding Author:-Nyabaro Obed Mainya.

Address:-Department of Chemistry, Kisii University, Kisii-Kenya. 
Acrylamide is a chemical substance formed by a reaction between amino acids and sugars. It typically occurs when foods with high starch content such as potatoes, root vegetables and bread, are cooked at high temperatures (over $120^{\circ} \mathrm{C}$ ) in a process of frying, roasting or baking.

Acrylamide is not deliberately added to foods instead it is a natural by-product of the cooking process and has always been present in our food. It is a chemical compound with the chemical formula $\mathrm{C}_{3} \mathrm{H}_{5} \mathrm{NO}$. Acrylamide has been classified as a Group 2A carcinogen and thus remains a suspected human carcinogen and a neurotoxicant that calls for a concerted effort to minimize its presence in all human diets [24].

Chips are among the starchy foods commonly used as a tuberous crop from the perennial night shade Solanum tuberosum. They have a high content of carbohydrates and vitamin $\mathrm{C}$ and thus, forming an important component of a balanced diet. With an annual global production of approximately 340 million tons of potatoes, therefore forms one of the world's chief staple foods. Worldwide, it is the fourth most widely grown food crop after rice, wheat and maize [14]. In Kenya, potato is the second most valuable cash and food crop after the cereal grains [9].

Acrylamide doesn't appear to be in raw foods themselves. It is formed when certain starchy foods are cooked at high temperatures that cause chemical reaction between sugars and an amino acid (asparagines) in the foods which forms acrylamide longer cooking times and cooking at higher temperatures on starchy foods increases the amount of acrylamide [5].

Acrylamide is formed in starchy foods heated at high temperatures either through frying or baking. The maillard reaction between the amino acid asparagine and reducing sugars or reactive carbonyls at temperatures above $120^{\circ} \mathrm{C}$ has been suggested as possible pathway for its formation in these foods [20]
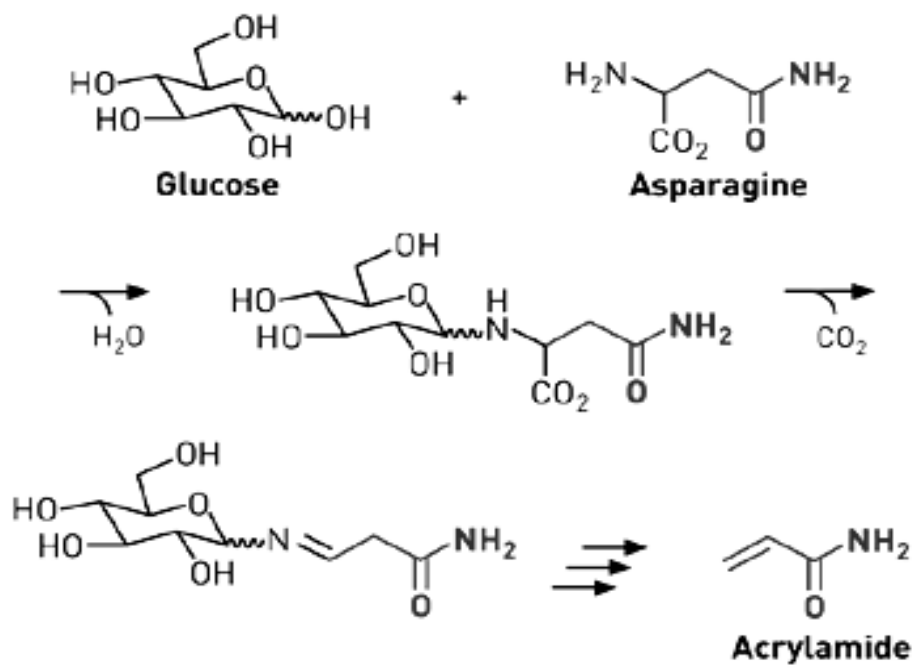

Figure1: Maillard reaction mechanism

Exposure to acrylamide can occur through inhalation of vapor, dust, or aerosol and absorption through the skin or mucous membranes. The current Occupational Safety and Health Administration (OSHA) permissible exposure limit (PEL) for acrylamide is $0.03 \mathrm{mg} / \mathrm{m}^{3}$ as an 8-hr time-weighted average (TWA) concentration. The OSHA PEL also bears a "Skin- designation, which indicates that the cutaneous route of exposure (including mucous membranes and eyes) contributes to overall exposure [22].

The National Institute for Occupational Safety and Health (NIOSH) has established a recommended exposure limit (REL) of 0.03 $\mathrm{mg} / \mathrm{m}^{3}$ as an 8-hr TWA with a "Skin" notation. However, acrylamide has been designated as a potential occupational carcinogen and exposure should be limited to the lowest feasible concentration [21].

The American Conference of Governmental Industrial Hygienists (ACGIH) has designated acrylamide an A2 substance (suspected human carcinogen) and assigned acrylamide a threshold limit value (TLV) of $0-03 \mathrm{mg} / \mathrm{m}^{3}$ as a TWA for a normal 8-hr workday and a 40-hr workweek with a "Skin" notation. All the above limits are based on the risk of systemic poisoning associated with exposure to acrylamide [2]. 
Conclusions from a consultation between FAO/WHO agreed that the "no observed adverse effect level" (NOAEL) for acrylamide neuropathy is $0.5 \mathrm{mg} / \mathrm{kg}$ body weight/day while that for fertility changes is four times higher than for peripheral neuropathy. The estimated average chronic human dietary intake is in the order of $1 \mu \mathrm{g} / \mathrm{kg}$ body weight/day which results in a margin between exposure and the NOAEL of 500 [40][41].

\section{Methodology:-}

Despite acrylamide being a relatively new contaminant for food analysts, intensive method development and refinement have been carried out. Various methods of determining the concentration of acrylamide in foods have been addressed. Among all these methods, three have been widely used for extraction and quantification of acrylamide in foods.

The samples were prepared for the analysis of potato chips and crisps by weighing $1 \mathrm{~g}$ of crushed potato chips and mixing with $10 \mathrm{~mL}$ methanol on a wrist action shaker for 20 minutes to enable the sample to fully soak in the extract solution. The samples were refrigerated for 2 minutes for easier extraction of the oily top layer to avoid interferences. The supernatant was filtered through a $0.45 \mu \mathrm{m}$ nylon syringe filter and the filtrate discarded and the residue stored for further cleanup and analysis.

The residue was conditioned through a carboPrep ${ }^{\mathrm{TM}} 200 \mathrm{SPE}$ tube using, $6 \mathrm{~mL}$ of the sample in $2 \mathrm{~mL}$ acetone and 2 $\mathrm{mL}$ methanol. The sample solution was allowed to pass through the tube by gravity and $0.5-1.0 \mathrm{~mL}$ water was run through the tube to wash the sample. A vacuum pump was used to dry excess water from tube for 1 minute and eluted with $2 \mathrm{~mL}$ of acetone through gravity therefore ready for analysis in the instrument. Many sample extracts can be analysed directly, however, sample cleanup and solvent pre-concentration was essential.

An isocratic elution pattern was adopted for the separation of the analyte, and 7\% (v/v) methanol in $0.025 \mathrm{~mol} / \mathrm{L}$ sodium dihydrogen phosphate was used as the mobile phase. The column temperature was set at $25^{\circ} \mathrm{C}$, the flow rate was maintained at $1.0 \mathrm{~mL} / \mathrm{min}$, while the detection was performed at $215 \mathrm{~nm}$. The injection volume was $20 \mu \mathrm{L}$ in the HPLC. By use of HPLC, the chromatographic separation is then done on; hydrophilic reversed phase, ion exchange column or carbon black.

\section{Results:-}

\section{Acrylamide Levels of potato chips and crisps}

Using HPLC, the study sought to determine the concentrations of acrylamide in the eight sub counties where potato French fries samples were obtained for the study. To ensure the correct identification of the compounds, three independent parameters i.e. mass spectra, chromatographic retention indexes, and partition coefficients, were used in the identification process. Mass spectra recorded during analyses were compared to the spectra contained in the National Institute of Standards and Technology (NIST) MS database. Determined retention indexes values and partition coefficients were compared to values from literature. The differential parameter $j$, which is a combination of $K_{p}$ and retention indices, was used additionally for identification of components. The $j$ parameter was calculated from equation:

$j=0.001 I-\log \mathrm{K}_{\mathrm{p}}$

The average the peak areas (or height) ratios of the eight samples from each sampling point were calculated by averaging the response ratios ( $r$ values). For each sample injection the response ratio $(r)$ is given by the equation:

$$
\mathrm{r}=\frac{\text { sample peak area }}{\text { area of internal standard peak }}
$$

The concentrations of the acrylamide from the spectra were calculated using the following formula:

Concentration in $(\mathrm{g} / \mathrm{kg})=\frac{\mathrm{r}_{2} * \mathrm{~m}_{1} * \mathrm{p}}{\mathrm{r}_{1} * \mathrm{~m}_{2}}$

Where $r_{1}$ is the average response ratio for calibration solution

$r_{2}$ is the average response ratio for sample solution

$\mathrm{m}_{1}$ is the mass of the organic contaminant standard in its calibration solution $(\mathrm{mg})$

$\mathrm{m}_{2}$ is the mass of sample taken (mg)

$\mathrm{P}$ is the purity of organic contaminant standard $(\mathrm{g} / \mathrm{kg})$ 
Table7: Chips samples

\begin{tabular}{|l|l|}
\hline $\begin{array}{l}\text { Sample } \\
\text { ID }\end{array}$ & $\begin{array}{l}\text { CONC } \\
\text { (mg/kg) }\end{array}$ \\
\hline C1 & 2.78367 \\
\hline C3 & 3.62797 \\
\hline C4 & 5.05677 \\
\hline CK8 & 1.60488 \\
\hline CK9 & 1.42343 \\
\hline CK10 & 5.07071 \\
\hline C12 & 1.81402 \\
\hline C13 & 1.44802 \\
\hline C14 & 3.38732 \\
\hline C15 & 2.81289 \\
\hline
\end{tabular}

In the results, Sample (CK10) is seen to have a high concentration of $5.07 \mathrm{mg} / \mathrm{L}$, compared to the other sampling points. This could be attributed to the high temperatures of cooking in Potato chips being that the locality is a major town and the residents highly consume this product due to the nature of their work on commercial breaks. Further, this is the major town that produces the Potato chips and from this town the majority of the population is the youth that relates the high intake hence constant cooking and high number of sales of the product. The high concentration of this sample could be due to using already hot cooking medium therefore high temperatures.

The findings of this study are in agreement with those of [6], who carried out a study on the concentration of acrylamide in Potato chips. Their findings indicate that acrylamide was detected in all samples, but its concentration varied significantly from 50 to $1800 \mu \mathrm{g} / \mathrm{g}$. Their statistical analysis indicated that the effect of sugars and asparagine on the concentration of acrylamide in Potato chips is positive and significant $(p<0.001)$ signifying that one of the ways acrylamide formation in potato chips was through cooking.

In this sample $\left(\mathrm{CK}_{10}\right)$ a high peak area mean is experienced compared to the other five sampling points. This could be attributed to the high temperatures of cooking in potato chips being that the locality is a major town and the residents highly consume this product due to the nature of their work on commercial breaks. Further, this is the major town that produces the potato chips and from this town the population the majority is the youth that relates the high intake hence constant cooking and high number of sales of the product.

Samples from Mogonga, Mwembe and Nyamataro seemed to be moderate in the levels of acrylamide. This could be due to the demand in the places are moderate while the temperature used is moderate.

Table 8: Acrylamide levels in crisps

\begin{tabular}{|l|l|}
\hline $\begin{array}{l}\text { Sample } \\
\text { ID }\end{array}$ & $\begin{array}{l}\text { CONC } \\
\text { (mg/kg) }\end{array}$ \\
\hline CK1 & 73.67321 \\
\hline CK2 & 20.08649 \\
\hline CK3 & 17.94632 \\
\hline CK4 & 34.67102 \\
\hline CK5 & 85.12951 \\
\hline CK6 & 19.08206 \\
\hline C16 & 35.49095 \\
\hline C17 & 88.44686 \\
\hline C18 & 60.37521 \\
\hline C19 & 75.5314 \\
\hline C20 & 121.0318 \\
\hline C21 & 127.4604 \\
\hline C22 & 83.04034 \\
\hline
\end{tabular}


WHO in conjunction with FAO has set a maximum permissible limit for acrylamide in food products at $0.5 \mathrm{mg} / \mathrm{kg}$ [42]. This implies that all the crisp samples had acrylamide levels higher than the permissible limits. However, the levels of acrylamide in the potato crisp samples were comparatively higher than the levels in Potato chips. This could be due to the high temperatures of cooking and size of the crisp.

Samples CK2, CK3 and CK6 were observed to be having extremely low levels of acrylamide. This could be due to the sample not being fully cooked due to low temperatures and the potatoes being mature while, samples C20 and C21 were observed to be containing extremely high amounts of acrylamide. This could be due to high temperatures, Maillard reaction due to browning or premature potatoes used. The samples could be further influenced by the effect of the small size of crisps that leads to complete cooking of the crisp and the locality or company producing the sample.

The high concentrations of acrylamide in the crisp samples are attributed to various factors. Firstly, state of maturity and storage conditions of the raw potatoes which influence sugars levels and hence directly affect the amount of acrylamide present in fried potato products [8]. The formation of acrylamide mainly occurs in plant based food stuffs through an irreversible combination of reducing sugars and amino acid mainly asparagine the maillard reaction[20]. The high concentrations of acrylamide can be attributed to the high frying temperatures. In this process, acrylamide formation begins at $120^{\circ} \mathrm{C}$ and optimal development occurs between $160^{\circ} \mathrm{C}-180^{\circ} \mathrm{C}$ [32]. The use of low frying temperature (under $160^{\circ} \mathrm{C}$ ) has been shown to reduces the concentration of acrylamide produced [26] but this negatively affect the quality characteristics of the product like texture, colour and oil content and consequently the acceptability of the product by the consumer may be reduced [26].

These results agree with those of [32] who assessed the concentration of acrylamide in potato crisps collected from Ibaraki, Japan. Her results showed that most of the potato crisps samples and showed acrylamide concentrations $>10.00 \mathrm{mg} / \mathrm{kg}$. Similar results were obtained by [23] who analyzed potato crisps purchased from Nairobi, Kenya. Her findings showed that the acrylamide levels significantly differed among the brands and place of purchase ranging from $5.67 \mathrm{mg} / \mathrm{kg}$ to $8.67 \mathrm{mg} / \mathrm{kg}$. All the samples had acrylamide concentrations high above the permissible limits. Dissimilar results were obtained by [31] who analyzed acrylamide concentration in potato crisps from Uppsala, Sweden. Their findings indicated that all the crisp samples purchased in Uppsala had acrylamide concentrations below $0.98 \mathrm{mg} / \mathrm{kg}$.

There was a statistically significant difference at the $p<.05$ level in Levels of acrylamide for the samples. Sampling points $[F(7,64)=86423.952, p<.001]$. This strongly shows the presence of acrylamide in the samples which proves the hypothesis on the presence of acrylamide.

The findings of this study are in agreement with those of [6] who carried out a study on the concentration of acrylamide in French Fries. Their findings indicate that acrylamide was detected in all samples, but its concentration varied significantly from 50 to $1800 \mu \mathrm{g} / \mathrm{g}$. Their statistical analysis indicated that the effect of sugars and asparagine on the concentration of acrylamide in French fries is positive and significant $(p<0.001)$ signifying that one of the ways acrylamide formation in French fries can be effectively controlled is by the use of raw products with low sugar content. [11] got similar results in their study of the relationship between the acrylamide formation and timetemperature history of surface and core regions of French fries.

The high concentrations of acrylamide in the crisp samples are attributed to various factors. Firstly, state of maturity and storage conditions of the raw potatoes which influence sugars levels and hence directly affect the amount of acrylamide present in fried potato products [9]. The formation of acrylamide mainly occurs in plant based food stuffs through an irreversible combination of reducing sugars and amino acid mainly asparagine the maillard reaction [16]. These results agree with those of [32] who assessed the concentration of acrylamide in potato crisps collected from Ibaraki, Japan. Her results showed that most of the potato crisps samples and showed acrylamide concentrations $>10.00 \mathrm{mgkg}^{-1}$. Similar results were obtained by [23] who analyzed potato crisps purchased from Nairobi, Kenya. Her findings showed that the acrylamide levels significantly differed among the brands and place of purchase ranging from $5.666 \mathrm{mg} / \mathrm{kg}$ to $8.666 \mathrm{mg} / \mathrm{kg}$. All the samples had acrylamide concentrations high above the permissible limits. Dissimilar results were obtained by [31] who analyzed acrylamide concentration in potato crisps from Uppsala, Sweden. Their findings indicated that all the crisp samples purchased in Uppsala had acrylamide concentrations below $0.98 \mathrm{mg} / \mathrm{kg}$. 


\section{Objective:-}

To determine the presence and levels of acrylamide in samples of potato chips and crisps obtained from retail outlets in Kisii, Kenya

\section{Conclusion:-}

Results of this study are clear that the intake of fried starchy foods should stop and From the study, results of cooked potato products, such as crisps and chips (potato chips), contribute a substantial proportion of the estimated intake of acrylamide in the population of Kisii and unless the consumption is reduced over time the acrylamide levels are likely to be increased in the human body therefore, potential increases the risk of developing cancer. Further efforts on developing and implementing mitigation methods for acrylamide in foods of major importance for dietary exposure" [33].

People should avoid fast starchy foods for they are rich in acrylamide and if not possible, encourage cooking of potato chips under low conditions but regulate the intake to avoid accumulation of the acrylamide in the body. Considerations should be made on the type of potato and effect in amount of acrylamide in the type of potato and region of collection since it is assumed that different soils have different nutrients in the outcome of planting potatoes.

Consideration should be made on observation of harvesting potatoes and raw potato pre-treatment to be made in an effort to reduce reducing sugars that aid in acrylamide formation.

\section{Refferences:-}

1. Abong, C. G. O. (2011). Effect of Slice Thickness and Frying Temperature on Colour, Texture and Sensory Properties of Crisps made from Four Kenyan Potato Cultivars 1Creorge C. Abong', 11Vlichael W. Ckoth, 1Jasper K. Imungi and 2Jackson N. Kabira. American Journal of Food Technology, 6(9), 753-762.

2. ACGIH (1991).1991-1992 Threshold limit values for chemical substances and physical agents and biological exposure indicesCincinnati, OH: American Conference of Governmental Industrial Hygienists.

3. Ahn, J. S., Castle, L., Clarke, D. B., Lloyd, A. S., Philo, M. R., \& Speck, D. R. (2002). Verification of the findings of acrylamide in heated foods. Food Additives and Contaminants 19, 1116-1124.

4. Albuquerque, T. G., Sanches-Silva, A., Santos, L., \& Costa, H. S. (2012). An update on potato crisps contents of moisture, fat, salt and fatty acids (including trans-fatty acids) with special emphasis on new oils/fats used for frying. International journal of food sciences and nutrition, 63(6), 713-717

5. American Cancer Society Medical and Editorial Content. (March, 2016).

6. Becalski, A., Lau, B.P.Y., Lewis, D.,Seaman, S.W., 2004. Acrylamide in foods:Occurrence, sources, and modeling. Journal of Agricultural and Food Chemistry 51, 802-808.

7. Burton, W.G.,A. van and K.J. Hartmans. (1992). The Physics and Physiology of Storage. $2^{\text {nd }}$ Edition Chapman Hall, London, U.K.

8. De Wilde, T., De Meulenaer, B., Mestdagh, F., Govaert, Y., Vandeburie, S., Ooghe, W., ... \& Verhé, R. (2005). Influence of storage practices on acrylamide formation during potato frying. Journal of Agricultural and Food Chemistry, 53(16), 6550-6557.

9. Gitau, M. (2013, December). Small scale growing business in Kenya Youth Agro Environment Initiative. Retrieved June 23, 2014, from http://yagrein.blogspot.com/2012/05/small-scale-es-growing-business.html

10. Gökmen, V., Palazoğlu, T. K., \& Şenyuva, H. Z. (2006). Relation between the acrylamide formation and timetemperature history of surface and core regions of French fries. Journal of Food Engineering, 77(4), 972-976.

11. Elmore, J. S., Koutsidis, G., Dodson, A. T., Mottram, D. S., \&Wedzeicha, B. L. (2005). Measurement of acrylamide and it's precursors in wheat and rye model systems. Journal of Agricultural and Food Chemistry In press.

12. Food and Agriculture Organization of the United Nations. World Health Organization (2014).Summary report of the sixty-fourth meeting of the Joint FAO/WHO Expert Committee on Food Additives (JECFA). Retrieved on June $25^{\text {th }}$ 2014:

13. Food and Drug Administration (FDA).(2003). Detection and quantitation of acrylamide in foods. Retrieved on June 26, 2014 From http:/www.cfsan.fda.gov/ dms/acrylami.html

14. Hijmans, R.J. \& Spooner, D.M. (2001).Geographic distribution of wild species.American Journal of Botany 88 (11): 2101-12.

15. Krokida, M. K., Oreopoulou, V., and Maroulis, Z. B. (2000). Water loss and oil uptake as a function of frying time. Journal of Food Engineering, 44(1), 39-46.

16. Mazza, G. (1983). Correlations between quality parameters of potatoes during growth and long term storage. Amer. Potato. 
17. Mendoza, F., Aguilera, J.M., (2004). Application of images analysis for classification of ripening bananas. Journal of Food Science 69, 471-477.

18. Mestdagh, F., De Wilde, T., Castelein, P., Németh, O., Van Peteghem, C., and De Meulenaer, B. (2008). Impact of the reducing sugars on the relationship between acrylamide and Maillard browning in French fries. European Food Research and Technology, 227(1), 69-76.

19. Ministry of Agriculture (MoA) (2005). Potato Standards In: The Crop Production and Livestock

20. Mottram, D., Wedzicha, B., and Dodson, A. (2002). Acrylamide is formed in the Maillard reaction. Nature, 419, 448449.

21. NIOSH (1991).NIOH and NIOSH basis for an occupational health standard. Acrylamide: a review of the literature. Cincinnati, OH: U.S. Department of Health and Human Services, Public Health Service, Centers for Disease Control, National Institute for Occupational Safety and Health, DHHS (NIOSH) Publication No. 91-115

22. Occupational Safety and Health Administration (OSHA). (2014). Safety Data Sheet acc. to OSHA HCS (V311). Madison, U.S.A.: OSHA.

23. Ogolla, J. A. (2013). Acrylamide Contamination In Commercial Potato Crisps In Kenya: Levels Of Intake And Effects Of Processing Parameters In Local Cultivars (Doctoral dissertation, University of Nairobi,).

24. Olesen, P.T., Olsen, A., Frandsen, H., Frederiksen, K., Overvad, K. \&Tjønneland, A. (2008)."Acrylamide exposure and incidence of breast cancer among postmenopausal women in the Danish Diet, Cancer and Health Study".International Journal of Cancer. Journal International Du Cancer 122 (9): 2094-100.

25. Ono, T., R. Guthold and K. Strong, 2012. WHO Global comparable estimates: Global Infobase data for saving lives 2005. https://apps.who.int/infobase/.

26. Pedreschi, F., Kaack, K., and Granby, K. (2004). Reduction of acrylamide formation in potato slices during frying. LWT-Food Science and Technology, 37(6), 679-685.

27. Pedreschi, F., Moyano, P., Kaack, K., and Granby, K. (2005). Colour changes and acrylamide formation in fried potato slices. Food Research International, 38(1), 1-9.

28. Pedreschi, F., Kaack, K., Granby, K., and Troncoso, E. (2007). Acrylamide reduction under different pre-treatments in French chips. Journal of food engineering, 79(4), 1287-1294.

29. Pedreschi, F., Segtnan, V. H., and Knutsen, S. H. (2010). On-line monitoring of fat, dry matter and acrylamide contents in potato chips using near infrared interactance and visual reflectance imaging. Food Chemistry, 121(2), 616-620.

30. Rommens, C. M., Yan, H., Swords, K., Richael, C., and Ye, J. (2008). Low-acrylamide French chips and potato chips. Plant biotechnology journal, 6(8), 843-853.

31. Rosén J., Hellenäs K.E. (2002). Analysis of acrylamide in cooked foods by liquid chromatography tandem mass spectrometry. The Analyst, 127(7): 880-882.

32. Stadler, R., Blank, I., Varga, N., Robert, F., Hau, J. r., Guy, P., Robert, M., and Riediker, S. (2002). Acrylamide from Maillard reaction products.Nature 419, 449-450

33. Svensson, K., Abramsson, L., Becker, W., Glynn, A., Hellenas, K.-E., Lind, Y., \& Rosen, J. (2003).Dietary intake of acrylamide in Sweden. Food and Chemical Toxicology 41, 1581-1586.

34. Sivasankar, B. (2002). Food Processing and Preservation.PHI Learning Pvt. Ltd. pp. 175-177.ISBN 8120320867

35. Taubert, D., Harlfinger, S., Henkes, L., Berkels, R., and Schömig, E. (2004). Influence of processing parameters on acrylamide formation during frying of potatoes. Journal of Agricultural and Food Chemistry, 52(9), 2735-2739.

36. Tareke, E. \& Rydberg, P. (2002). "Analysis of acrylamide, a carcinogen formed in heated foodstuffs". J. Agric. Food. Chem.50 (17): 4998-5006.

37. Van Arsdel,W., Copley, M., \& Morgan, A. (1973). Food Dehydration. (2nd Edition). Westport, CN: The Avi Publishing Company, Inc.

38. Viklund, G., Mendoza, F., Sjöholm, I., and Skog, K. (2007). An experimental set-up for studying acrylamide formation in potato crisps. LWT-Food Science and Technology, 40(6), 1066-1071.

39. WHO. Health Implications of Acrylamide in Food: Report of a joint FAO/WHO consultation, Headquarters, Geneva, Switerland, 25-27 June 2002. Geneva: WHO; 2002.

40. WHO (2002). FAO/WHO Consultation on the Health Implications of Acrylamide in Food.

41. WHO (2002).FAO/WHO Consultation on the Health Implications of Acrylamide in Food.Summary Report of a meeting held in Geneva, 25-27 June 2002.

42. WHO Technical Report Series No. 959. (2011). Evaluation of Certain Contaminants in Food. Seventy-second report of the Joint FAO/WHO Expert Committee on Food Additives. World Health Organization.

43. Xu, Y; Cui, B; Ran, R; Liu, Y; Chen, H; Kai, G; Shi, J. (2014). "Risk assessment, formation, and mitigation of dietary acrylamide: Current status and future prospects.".Food and chemical toxicology : an international journal published for the British Industrial Biological Research Association69C: 1-12. 